\title{
A smart approach for delivery of aripiprazole via oro-soft palatal mucosal route for improved therapeutic efficacy
}

\author{
Nookala Venkala Satheesh Madhav ${ }^{1 *}$, Abhijeet Ojha ${ }^{1}$, Vishakha Jaiswal ${ }^{1}$ \\ ${ }^{I}$ Drug Delivery Research Lab, Faculty of Pharmacy, DIT University, Makkawala, P.O. Bhagwantpur, Dehradun, \\ Uttarakhand, India
}

\begin{abstract}
Effective management of schizophrenia, acute mania, mixed episodes associated with bipolar disorders, and depression can be managed with aripiprazole moiety. In the present research work an attempt was made to minimize the dose related side effects thus improving the quality life of the patients. A novel biopolymer was isolated from the fruits of Trachyspermum ammi. Ten optimized nanosized aripiprazole loaded formulations were prepared in 1-5\% concentration of biopolymer (FA1-FA5) and sodium CMC (FM1-FM5) by solvent casting technique. The formulated flexy films were evaluated for thickness, folding endurance, weight uniformity, surface $\mathrm{pH}$, mucoadhesivity, In-vitro drug release studies, In-vivo pharmacodynamic study and stability studies. The isolated biopolymer showed inbuilt fimability and mucoadhesivity and consists of carbonyl, hydroxyl and thiocarbonyl functional groups. All formulations showed folding endurance from 153 to 170 , mucoadhesion time in the range of 24-48hrs., and in-vitro drug release was performed using dynamic Franz Diffusion cell and analyzed using BIT-SOFTWARE. The experimental animals showed improved activity score on actophotometer. The formulated nanosized aripiprazole loaded bio-flexy films showed pharmacotherapeutic response. Conclusion can be drawn that optimized formulation showed effective Pharmacodynamic activity and can be used as for improving therapeutic efficacy of aripiprazole through this platform.
\end{abstract}

Keywords: Aripiprazole/therapeutic efficacy. Nanosized. Mucoadhesive. Schizophrenia. Oro-soft palatal mucosal route.

\section{INTRODUCTION}

Schizophrenia is self-disorder characterized by complementary distortions of the act of awareness i.e. hyperreflexivity and diminished self-affection (Sass, Parnas, 2003). Studies had suggested that the etiology of schizophrenia is yet unclear but it is believed that dopaminergic neural network has major role in its pathophsiology (Nekovarova et al., 2014). The symptoms of schizophrenia are positive and negative symptoms, and cognitive effects. The positive symptoms are conceptual disorganization, abnormal thought contents and hallucinations. Negative symptoms are reduction in normal functioning, flattened emotions, decrease of social behavior and anhedonia. Cognition is affected in several arena such as vigilance, psychomotor speed, impairment

\footnotetext{
*Correspondence: N.V. Satheesh Madhav. DIT-Faculty of Pharmacy, DIT University, Makkawala, P.O. Bhagwantpur, Dehradun, Uttarakhand, India, 248009. E-mail: satheesh_madhav@yahoo.com
}

of memory functioning, social cognition (Green et al., 2004).

Aripiprazole is used for the treatment of schizophrenia, bipolar disorder, major depressive disorder, autism, and Tourette's syndrome (USFDA approved label of ABILIFY). It is a second generation atypical antipsychotic which belongs to the benzisoxazole derivatives and has serotonin 5-HT1A-receptor partial agonist as well as 5- HT2A-receptor antagonist properties like a partial agonist at dopamine $\mathrm{D} 2$ receptors. It has a pKa value of 7.6 in 20\% aqueous ethanol (Ardiana, Lestari, Indrayanto, 2013). Aripiprazole is a poorly soluble and poorly permeable compound with BCS class IV (Laszcz, Witkowska, 2016). It is weak alkaline drug which thus imparts $\mathrm{pH}$-dependent solubility to it ( $\mathrm{Xu}$ et al., 2012).

Aripiprazole is categorized under black box warning drugs as it increases the risk of death in geriatric patients having dementia-related psychosis when treated with antipsychotic drugs. This may be due to collapse, 
infection or stroke. Also increases suicidal thinking and behavior in children, adolescents, and young adults taking antidepressants. Depression and other serious mental illnesses are themselves associated with an increased risk of suicide (Kalinichev et al., 2005; Otsuka Pharmaceutical, 2002).

The soft palate is the soft tissue present at the back of the roof of the mouth. The soft palatal mucosa is flexible, highly vascularized, having nonkeratinized stratified squamous epithelium about 100-200 $\mu \mathrm{m}$ thick, and it is supposed to be 4-4000 times more permeable than skin. The seromucous glands secrete saliva and facilitate adhesion. The blood supply to the palatal region comes from facial artery and is $0.89 \mathrm{~mL} / \mathrm{min} / 100 \mathrm{~cm}^{2}$. It is innervated through CN V (i.e. lesser palatine nerve) (Shankar, Madhav, 2015; Shakya, Madhav, Shakya, 2011).

The plant Trachyspermum ammi belonging to family Apiaceae, is commonly known as ajwain. The fruits are used as spice and available in the market whole year. The phytochemical analysis of plant showed 38.6\% carbohydrate, $15.4 \%$ protein, $11.9 \%$ fiber and $7.1 \%$ minerals containing calcium, phosphorous, iron and nicotinic acid (Bairwa, Sodha, Rajawat, 2012). As on date literature reveals that no attempt was made for isolating biopolymer from Trachyspermum ammi, novel approach was made for isolating biopolymer from Trachyspermum ammi.

The current objective of our research work was to improve therapeutic efficacy of aripiprazole by delivering nanosized aripiprazole through soft palatal route. This can be achieved by formulating mucoadhesive bio-flexy film.

\section{MATERIAL AND METHODS}

Aripiprazole was received as gift sample from Sun Pharma (Mumbai), India. Trachyspermum ammi was procured from local market of Dehradun, Uttarakhand, India. Sodium CMC, D-glucose, 1,2,3-propanetriol and all other chemicals and solvents were of analytical reagent grade.

\section{Isolation of biomaterial from the pulp of Trachyspermum ammi}

250 grams fruits of Trachyspermum ammi were taken soaked in distilled water and subjected for hydro distillation using Clevenger's apparatus for $48 \mathrm{~h}$, filtered and air dried. Exhausted seeds were mixed with $250 \mathrm{~mL}$ distilled water in a mixer to get smooth slurry and it was filtered through a muslin cloth. The filtrate was centrifuged at $3000 \mathrm{rpm}$ to remove the extraneous matter. The supernatant liquid was treated with optimized quantity of propanone and kept in refrigerator for $24 \mathrm{~h}$. The bio-material was separated by centrifugation at $4000 \mathrm{rpm}$ for $25 \mathrm{~min}$. The bio-material was dried in desiccator for $48 \mathrm{~h}$. The bio-material extraction was repeated 6 times \& practical yield was reported (Madhav, Shankar, 2011).

\section{Physico-chemical characterization and spectral analysis of the isolated bio-material}

The isolated bio-material was tested for various physico-chemical properties like colour, odour, solubility, color changing point, chemical tests for carbohydrates (molisch test, benedict's), proteins (biuret test) and starch, and spectral studies like I.R Spectra was performed using Shimadzu IR Tracer-100.

\section{In-vitro mucoadhesivity study of isolated bio-polymer}

The isolated bio-polymers were screened for mucoadhesivity. The films were prepared in the ratios of $1-5 \% \mathrm{w} / \mathrm{v}$ biopolymer from $T$. ammi. The biopolymer was accurately weighed in different ratios and triturated with $10 \mu \mathrm{L}$ of 1,2,3-propanetriol, and $80 \mathrm{mg}$ of D-glucose as flexicizer. $10 \mathrm{~mL}$ of distilled water added into it and subjected for mechanical stirring for $30 \mathrm{~min}$. The resulting solution was poured on petridish for natural drying of about $24 \mathrm{~h}$. The dried bio-flexy films were tested for mucoadhesivity by Rotating Cylinder Method using Type II Dissolution apparatus goat intestinal mucosa. The fresh intestinal mucosa was attached over the cylindrical basket. The prepared flexy films were adhered to the membrane with gentle pressing. Then the cylinders were rotated at $100 \mathrm{rpm}$ in $900 \mathrm{~mL}$ of $\mathrm{pH}$ buffer 7.4 at $37 \pm^{\circ} \mathrm{C}$. The films were observed at different time intervals and the time required for dislodgement and or disintegration was recorded (Madhav, Yadav, 2013).

\section{Drug excipients interaction study}

The drug interaction study was performed wet and dry method. The drug was physically mixed with excipients in dry method and in wet method the physical mixture was treated with $2 \mathrm{~mL}$ of distilled water in the ratios of 1:1, 1:3 and 3:1 and kept for a period of 3 days. Both the mixtures were dissolved in methanol and then analyzed by TLC and UV Spectrophotometric method at $221 \mathrm{~nm}$ (Kalaichelvi et al., 2009). 


\section{Formulation of nanosized Aripiprazole loaded flexy films}

Aripiprazole was nanosized by using Novel method. The drug was dissolved in suitable solvent and $10 \mu \mathrm{L}$ of 1,2,3-propanetriol was added as nanosizant into it. Propanetriol has the ability to enhance the wettability of aripiprazole and serves as good dispersing agent who aids in nanosizing of the particle hence it acts as nanosizant (Nalawde, Mukherjee, Kapoor, 2013).

$10 \mathrm{~mL}$ of distilled water was added into it and sonicated for 5 cycles (each cycle of 3 mins). The solution was micro centrifuged at 10,000rpm for $15 \mathrm{~min}$ and residue was dried and collected. Optimized nanosized aripiprazole loaded flexy films using biopolymer and standard film former i.e. sodium CMC were prepared by using "Solvent casting method". In this method biopolymer from T. ammi and sodium CMC was accurately weighed in different ratios and triturated with $10 \mu \mathrm{L}$ of 1,2,3-propanetriol, and $80 \mathrm{mg}$ of D-glucose as flexicizer. $10 \mathrm{~mL}$ of distilled water added into it and subjected for mechanical stirring for $30 \mathrm{~min} .10 \mathrm{mg}$ of drug was dissolved separately in ethanol. The nanosized drug solution was added to the polymeric solution under stirring 4,500 rpm. The polymeric solution was poured on petridish for natural drying of about $24 \mathrm{~h}$.

\section{Nanosizing characterization by U.V spectroscopic method}

It is a novel preliminary screening method for nanosizing range of particles by U.V spectroscopy and performed after each cycle of sonication. Transmittance is based on the concept of Tindal effect. When a light passes through a medium or solution which doesn't contain solute between $200-400 \mathrm{~nm}$ size range $100 \%$ light gets transmitted. If a solvent contains any solute particles ranging $200-800 \mathrm{~nm}$ then the particles may absorb a light and proportionally shows absorbance by reducing the $\% \mathrm{~T}$ 0.05 by reducing / blocking $10 \%$ of absorbance and $90 \%$ of transmittance similarly $1 \%$ absorbance with $10 \%$ T and 90\% blockage (Varley, 2005).

\section{Evaluation of nanosized aripiprazole loaded flexy films}

Appearance, weight uniformity and content uniformity study

All the flexy films were weighed three times then weight uniformity was calculated. All formulated flexy films were evaluated for its drug content uniformity. Selected film $\left(1 \mathrm{~cm}^{2}\right)$ was transferred into a $100 \mathrm{~mL}$ volumetric flask containing $7 \mathrm{~mL}$ of phosphate buffer of pH7.4 and $1 \mathrm{~mL}$ of methanol. The contents of flask were stirred for $4 \mathrm{~h}$ on magnetic stirrer. The drug content was then determined after appropriate dilutions by using an UV spectrophotometer (Shimadzu 1800) (Madhav, Yadav, 2013).

The drug content was calculated by using below equation:

Drug content $=($ Analyzed content $/$ Theoretical content $)$

$\mathrm{x} 100$

TABLE I - Formulation table of optimized aripiprazole loaded bio-flexy films of Trachyspermum ammi

\begin{tabular}{lccccc}
\hline Formulation & FA1 (1:1) & FA2 (1:2) & FA3 (1:3) & FA4 (1:4) & FA5 (1:5) \\
\hline Aripiprazole $(\mathrm{mg})$ & 10 & 10 & 10 & 10 & 10 \\
Trachyspermum ammi $(\mathrm{mg})$ & $1 \%$ & $2 \%$ & $3 \%$ & $4 \%$ & $5 \%$ \\
D-glucose (mg) & 80 & 80 & 80 & 80 & 80 \\
1,2,3-Propanetriol $(\mu \mathrm{L})$ & 10 & 10 & 10 & 10 & 10 \\
Distilled Water $(\mathrm{mL})$ & 10 & 10 & 10 & 10 & 10 \\
\hline
\end{tabular}

TABLE II - Formulation table of optimized aripiprazole loaded flexy films of sodium CMC as Film former

\begin{tabular}{lccccc}
\hline Formulation & FM1 (1:1) & FM2 (1:2) & FM3 (1:3) & FM4 (1:4) & FM5 (1:5) \\
\hline Aripiprazole (mg) & 10 & 10 & 10 & 10 & 10 \\
Sodium CMC (mg) & $1 \%$ & $2 \%$ & $3 \%$ & $4 \%$ & $5 \%$ \\
D-glucose (mg) & 80 & 80 & 80 & 80 & 80 \\
1,2,3-Propanetriol $(\mu \mathrm{L})$ & 10 & 10 & 10 & 10 & 10 \\
Distilled Water $(\mathrm{mL})$ & 10 & 10 & 10 & 10 & 10 \\
\hline
\end{tabular}




\section{Folding endurance and surface $\mathrm{pH}$}

The selected films were subjected repeatedly folding a film (of area $2 \mathrm{~cm}^{2}$ ) at the same place until it broke and the number of folds recorded. The surface $\mathrm{pH}$ of flexy films was measured by using $\mathrm{pH}$ meter (Madhav, Yadav, 2013).

\section{Mucoadhesion study}

The mucoadhesive property of prepared films was evaluated by Rotating Cylinder method using goat soft palatal mucosa with phosphate buffer $\mathrm{pH}$ 7.4. After each $30 \mathrm{~min}$ and up to $36 \mathrm{~h}$ the film was observed for any dislodgement or disintegration from the soft palatal mucosal surface. The results were compared with the standard films of sodium CMC (Madhav, Yadav, 2013).

\section{In-vitro drug release study}

The In-vitro drug diffusion was carried out by using the Dynamic Franz diffusion cell method. Egg shell membrane was tied on the donor compartment and flexy film of $1 \mathrm{~cm}^{2}$ area was kept on the above the membrane and the receiver compartment were filled with $7 \mathrm{~mL}$ of phosphate buffer $\mathrm{pH} 7.4 .4 \mathrm{~mL}$ of sample was withdrawn at the intervals of $0,10,20,30,60,120,180,300,360,480$ and $1440 \mathrm{~min}$ and replaced with $4 \mathrm{~mL}$ of fresh medium. The amount of drug released was assessed by measuring the absorbance at $221 \mathrm{~nm}$ using UV spectrophotometer (Shimadzu 1800) (Madhav, Yadav, 2013; Kalaichelvi et al., 2009).

\section{In-vivo pharmacodynamic study}

The in-vivo pharmacodynamic study was performed by monitoring locomotor activity of Wistar albino rats using actophotometer. Rats were divided into two test groups (group I \& II) and control (group III) each group containing two rats. Animals were maintained under light and dark cycle of $12 \mathrm{~h}$ in light and $12 \mathrm{~h}$ in dark under $25^{\circ} \mathrm{C}$ and $70 \% \mathrm{RH}$. Animals were placed in actophotometer individually and basal activity score was recorded over the period of $5 \mathrm{~min}$. Then the flexy film containing $1 \mathrm{mg}$ of aripiprazole was applied on the soft palatal mucosa of test group I, group II received oral solution of aripiprazole and activity score was recorded after $30 \mathrm{~min}$ and $1 \mathrm{hr}$ (Bhosale et al., 2011).

\section{Stability study}

Optimized best flexy film was subjected to stability study as per ICH guidelines. The film were kept in an incubator (stability study chamber) maintained at $37 \pm 5{ }^{\circ} \mathrm{C}$ and $75 \pm 5 \%$ R.H. for 6 months. The change in appearance, physical characteristics and release behavior of the stored films were investigated from 0-6 months (Ezhumalai et al., 2011).

\section{RESULTS AND DISCUSSION}

\section{Isolation, physico-chemical characterization and Spectral analysis of isolated bio-material from Trachyspermum ammi}

The \% yield of Trachyspermum ammi was found to be $5.1 \pm 1.05 \%$. The isolated biomaterial is carbohydrate and proteinaceous in nature. The physico-chemical characterization is shown in table IIIa and IIIb). The bio-material was purified by hot dialysis method and it was devoid of chlorides and sulfates. The functional groups of bio-material were elucidated by I.R. spectral studies.

TABLE IIIA - Characterization of bio-materia

\begin{tabular}{cccc}
\hline S.No. & Test & Observation & Inference \\
\hline 1. & Molisch & + & Carbohydrate present \\
2. & Benedict & + & Carbohydrate present \\
3. & Biuret & + & Proteins present \\
\hline
\end{tabular}

TABLE IIIB - Characterization of bio-material

\begin{tabular}{lc}
\hline Colour & Brown \\
Odour & Characterstic \\
Taste & Characterstic \\
Solubility & Slightly soluble in water \\
Melting Point & $255 \pm 10^{\circ} \mathrm{C}$ \\
\hline
\end{tabular}

The I.R. spectral interpretation by IR Pal V 2.0 reported the presence of hydroxyl $\left(3408 \mathrm{~cm}^{-1}\right)$, alkanes, alkenes, phosphonic $\left(2668 \mathrm{~cm}^{-1}\right)$, phosphine $\left(2430 \mathrm{~cm}^{-1}\right)$, amides $\left(1636 \mathrm{~cm}^{-1}\right)$, carboxylic acid $\left(1398 \mathrm{~cm}^{-1}\right)$, thiocarbonyl $\left(1117 \mathrm{~cm}^{-1}\right)$ and alkyne $\left(620 \mathrm{~cm}^{-1}\right)$. (Figure 1). These functional groups are responsible for the mucoadhesive property of the biopolymer.

\section{In-vitro mucoadhesivity study of isolated bio-polymer}

The isolated biopolymer showed maximum mucoadhesion time of $48 \mathrm{hrs}$ at the concentration of $5 \%$. The results revealed that as the concentration of biopolymer was increased there was also an increase in mucoadhesion time which can be explored for designing mucoadhesive dosage form (Figure 2). 


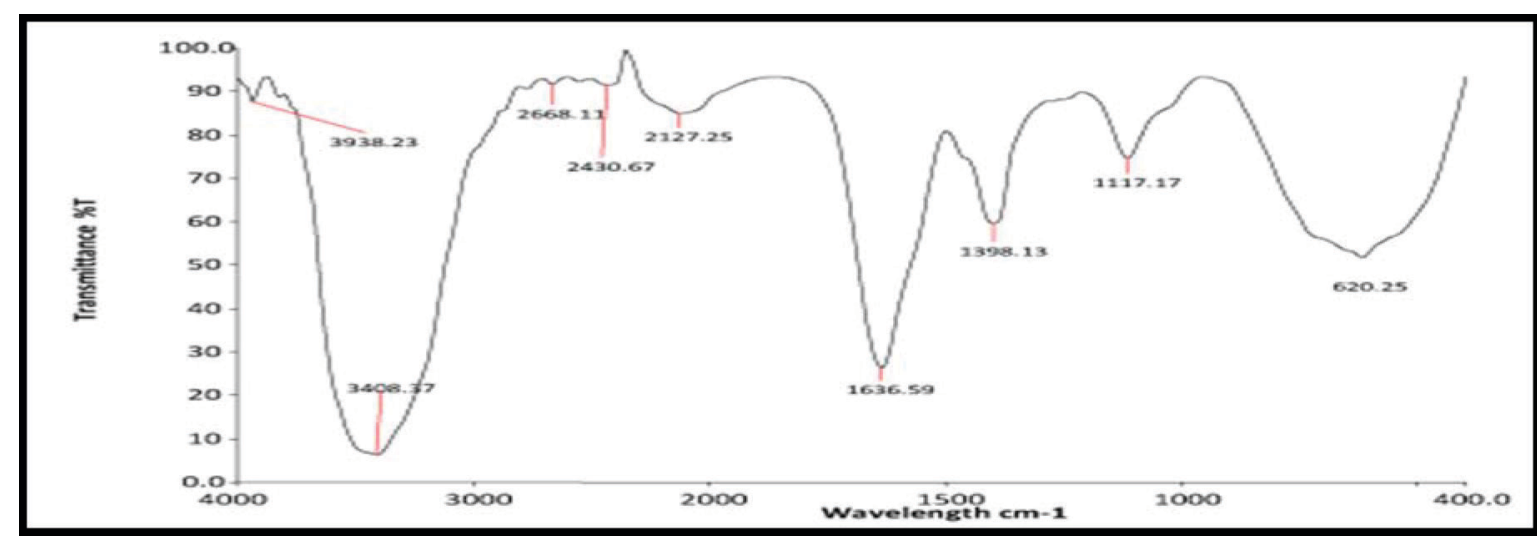

FIGURE 1 - I.R. Spectra of Trachyspermum ammi.

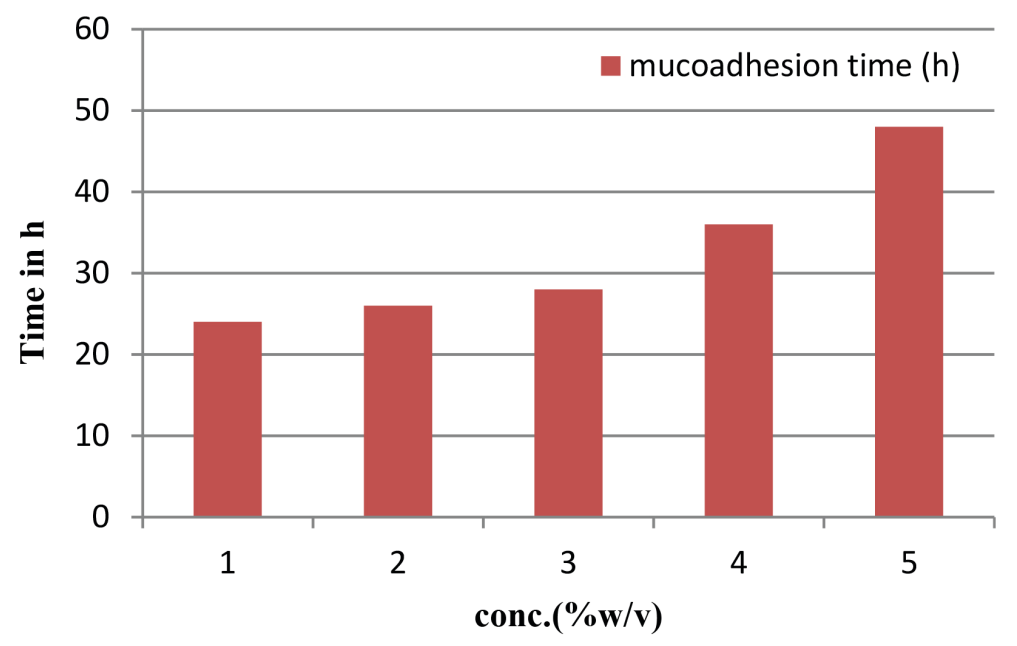

FIGURE 2 - In-vitro Mucoadhesion study of isolated bio-polymer.

\section{Drug excipients interaction study}

The studies revealed that there was no interaction between the drug and the excipients including the biopolymer. This was confirmed by the result of the thin layer chromatography in which no change was seen in the $\mathrm{Rf}$ value. Also there was no change in the $\chi$ max and absorbance also. Since excipients doesn't have any reacting group hence selected for further processing. Value which was observed to be $221 \mathrm{~nm}$ prior to the test and after the test it was 221 nm hence confirming that there was no interaction between the drug and excipients. It was concluded that none of the excipients had a deleterious effect on the drug and could be used for the formulation of the flexy-films.

\section{Nanosizing characterization by U.V spectroscopic method}

$\%$ Transmittance was measured before and after each cycle of sonication. As the number of sonication cycles was increased there was an increase in the $\%$ transmittance indicating that the particles may be gone in nano range thus increasing the transmittance (Figure 3 ).

\section{Evaluation of prepared nanosized aripiprazole loaded flexy films}

Nanosized Aripiprazole loaded bio-flexy films (FA1-FA5 and FA1-FA5) were prepared by using biopolymer isolated from Trachyspermum ammi as mucoadhesive film former, sodium CMC as standard polymer, D-glucose as flexicizer and other co-processing agent like 1,2,3-propanetriol as plasticizer.

All the prepared formulations were subjected for different evaluation parameters.

\section{Appearance, weight uniformity and content uniformity study}

All flexy films were transparent in nature, smooth in appearance, and flexible in nature. The weight variation 


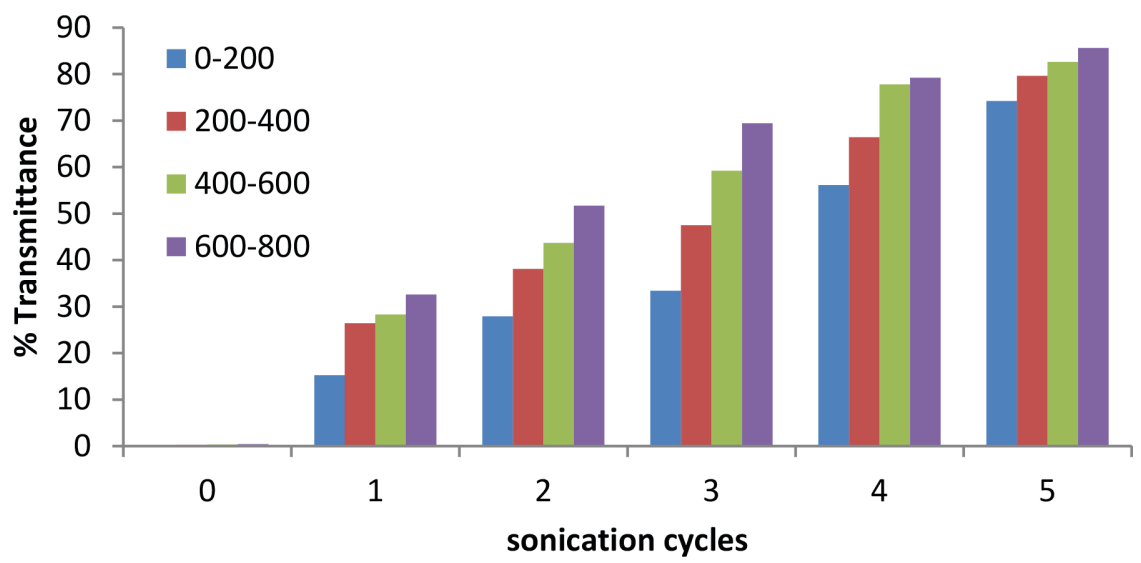

FIGURE 3 - Nanosizing charaterization by UV spectroscopic method.

and $\%$ drug content of all the flexy film formulas was in the range of 23.73 to $34.48 \mathrm{mg}$ and $96.4-98.9 \%$ respectively as shown in Table IV.

\section{Folding endurance and surface $\mathrm{pH}$}

The results were shown in the Table IV. All the prepared formulations (FA1-FA5 and FM1-FM5) showed folding endurance in the range of 153 to 170 folds. Folding endurance study revealed that there was slight increase in the flexibility of the films as the polymeric concentration was increased in the formulations. FM5 showed maximum folding endurance of 170 times in comparison to other formulations, this may be due to the presence of optimum concentration of polymer and flexicizer. FA1 showed minimal folding endurance of 153 times. All the prepared formulations (FA1-FA5 and FM1-FM5) showed a surface $\mathrm{pH}$ in the range of 7.31 to 7.41 which is near to neutral in nature and devoid of irritation as formulations were prepared by using biopolymeric substance which is edible, biocompatible, economical and devoid of any mucosal irritant groups.

\section{Mucoadhesion study}

The mucoadhesion of the prepared films was assessed by in-vitro Rotating Cylinder method using goat soft palatal mucosa. All the formulations showed significant mucoadhesion time and as the concentration of polymer was increased there was proportional increase in the mucoadhesion time. (Figure 4) The In-vitro mucoadhesion study showed that formulation FA5 and FM5 had maximum mucoadhesion for a period of $48 \mathrm{~h}$. This may be due to presence of mucoadhesive functional groups like carboxylic and thiocarbonyl and optimized proportion of polymer. FA1 showed least mucoadhesion time over a period of $22 \mathrm{~h}$ this may be due to the minimum concentration of biopolymer and/or overdhyration.

TABLE IV - The pH, weight, folding endurance and percent of drug content in Aripiprazole loaded flexy film formulations

\begin{tabular}{ccccc}
\hline $\begin{array}{c}\text { Formulation } \\
\text { Code }\end{array}$ & pH & $\begin{array}{c}\text { Weight Uniformity } \\
(\mathbf{m g})\end{array}$ & $\begin{array}{c}\text { Folding Endurance } \\
\text { (folds) }\end{array}$ & \% Drug content \\
\hline FA1 & $7.41 \pm 0.05$ & $21.89 \pm 0.06$ & $153 \pm 0.5$ & $97.1 \pm 0.04$ \\
FA2 & $7.38 \pm 0.07$ & $24.54 \pm 0.05$ & $156 \pm 0.6$ & $98.9 \pm 0.03$ \\
FA3 & $7.35 \pm 0.08$ & $25.73 \pm 0.07$ & $154 \pm 0.4$ & $98.3 \pm 0.05$ \\
FA4 & $7.33 \pm 0.06$ & $24.71 \pm 0.06$ & $157 \pm 0.2$ & $97.4 \pm 0.07$ \\
FA5 & $7.35 \pm 0.05$ & $23.98 \pm 0.08$ & $162 \pm 0.3$ & $96.8 \pm 0.05$ \\
FM1 & $7.31 \pm 0.04$ & $22.73 \pm 0.03$ & $164 \pm 0.7$ & $98.4 \pm 0.04$ \\
FM2 & $7.40 \pm 0.06$ & $23.56 \pm 0.04$ & $162 \pm 0.2$ & $98.5 \pm 0.04$ \\
FM3 & $7.39 \pm 0.05$ & $24.78 \pm 0.06$ & $163 \pm 0.3$ & $96.4 \pm 0.03$ \\
FM4 & $7.34 \pm 0.06$ & $23.01 \pm 0.05$ & $167 \pm 0.4$ & $96.8 \pm 0.05$ \\
FM5 & $7.33 \pm 0.07$ & $24.48 \pm 0.07$ & $170 \pm 0.5$ & $97.2 \pm 0.04$ \\
\hline
\end{tabular}


Upon increasing the biopolymer and standard polymer concentration there was an appreciable increase in the mucoadhesion time.

\section{In-vitro drug release study}

The In-vitro drug release kinetics was analyzed by BIT-SOFTWARE. The t50\% and $\mathrm{t} 80 \%$ of formulations were calculated and reported.

The comparative drug release profile of all the formulations showed that the drug released followed the descending order: FA $2>$ FM $1>$ FA $4>$ FM $5>$ FA $5>$ FM3 $>$ FA1 $>$ FA3 $>$ FM4 $>$ FM2 (Figure 5).

The In-vitro drug release study revealed that formulation $\mathrm{t} 50 \%$ from $3.1-4.5 \mathrm{~h}$, and released drug up to $24 \mathrm{~h}$. Biopolymer showed drug release retardation property and released drug for a longer period of time thus reducing the dosing frequency.

\section{In-vivo Pharmacodynamic study}

The photoactometer study showed the evidence of greater central nervous system stimulation by the nanosized drug loaded flexy film application in rats of group I in the form of increased activity score. While the rats in test group II does not showed comparable increase in activity score (Figure 6).

The results of in-vivo Pharmacodynamic study showed that there was increase in the locomotor activity of experimental animals (group I) after flexy film application, signifies the increased dopaminergic activity in brain. Comparing the results it suggested that the

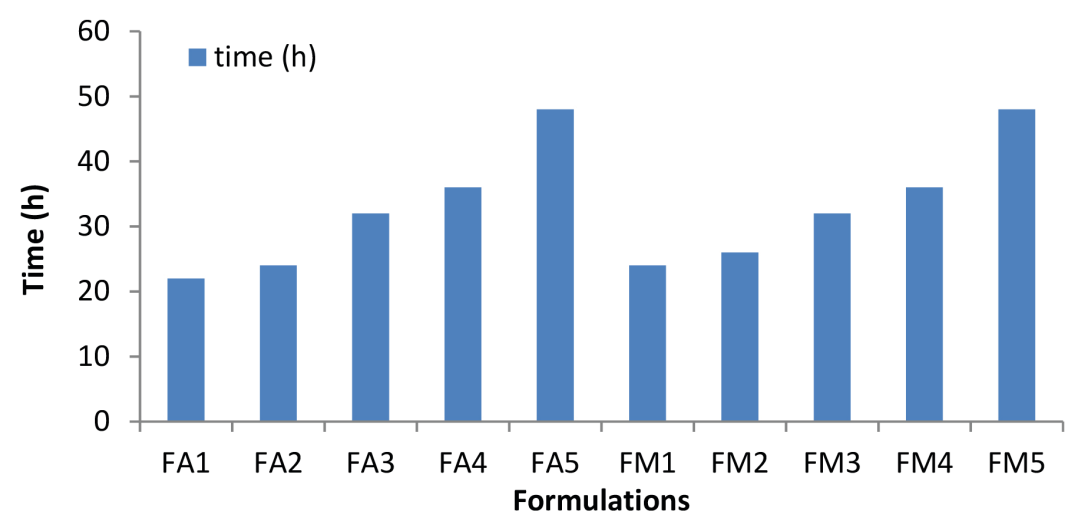

FIGURE 4 - In-vitro Mucoadhesion Study by Rotating Cylinder Method.

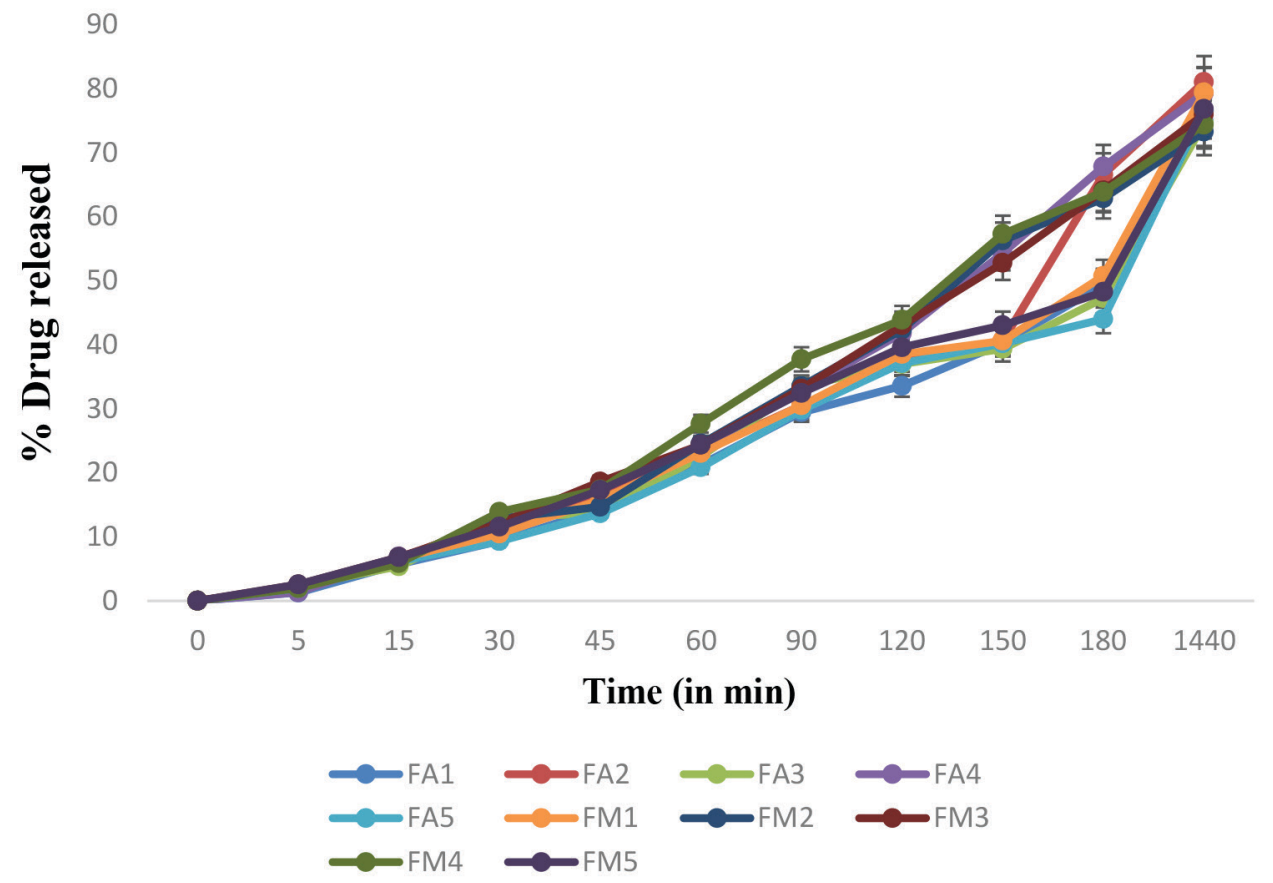

FIGURE 5 - In-vitro drug release study by franz diffusion cell apparatus. 


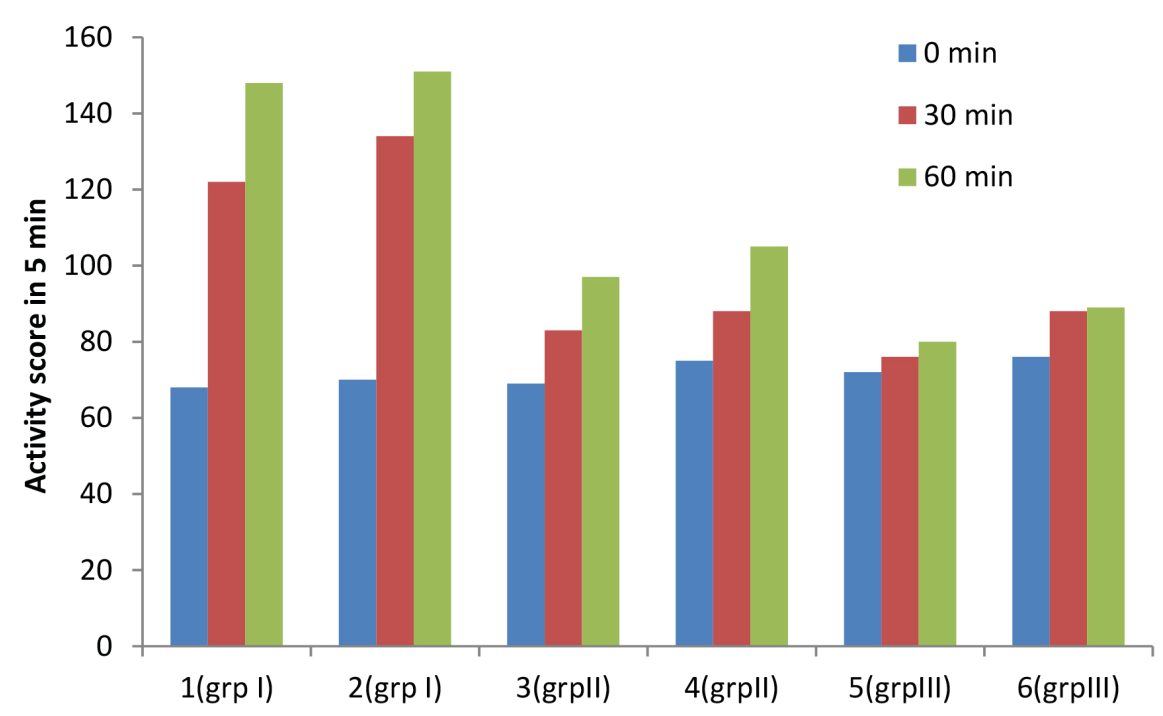

FIGURE 6 - Pharmacodynamic study by Photoactometer.

locomotor acitivity due to the drug was much more in the group receiving nanosized aripiprazole than the group administered with plain oral solution of drug at same dose level.

\section{Stability study}

The best formulation was stable over a period of 6 months as there was no change in the physical appearance, drug content and in-vitro release.

On comparison of the performance of all flexy films including texture, flexibility, surface $\mathrm{pH}$, weight uniformity, content uniformity, folding endurance, mucoadhesivity, In-vitro drug release retardibility, invivo Pharmacodynamic study the FA2 formulation with $\mathrm{R}^{2}$ value 0.9121 was selected as best optimized film. The above results indicated that administration of nanosized Aripiprazole via oro-soft palatal route increased its therapeutic performance

\section{CONCLUSION}

The isolated biopolymer from Trachyspermum ammi can serve as film former and it can be used for designing various drug loaded flexy films. Delivery of aripiprazole can be significantly enhanced by administering in the form of nanosized aripiprazole loaded bio-flexy film on soft palatal mucosa as it is enriched with nerve supply, so it showed significant Pharmacodynamic activity. Hence it was concluded that oro-soft palatal mucosa can serve as novelistic platform for effective delivery of Aripiprazole to produce significant Pharmacodynamic response.

\section{FINANCIAL SUPPORT AND SPONSORSHIP}

Nil.

\section{ACKNOWLEDGEMENTS}

We would like to thank Vice Chancellor and DIT University, Dehradun for their valuable support.

\section{CONFLICT OF INTEREST}

NA

\section{LIST OF ABBREVIATIONS}

t50\% - Time to release 50 percent of the drug t $80 \%$ - Time to release 80 percent of the drug $\mathrm{R}^{2}$ - Regression coefficient BBB - Blood Brain Barrier $\log \mathrm{P}$ - Partition coefficient $\mathrm{CN}$ - Cranial Nerve rpm - Resolution per minute $\mu \mathrm{L}$ - Micro liters Eq - Equa

\section{REFERENCES}

Ardiana F, Lestari MLAD, Indrayanto G. Profiles of drug substances, excipients, and related methodology. Amsterdam: Elsevier; 2013. p. 36-37.

Bairwa R, Sodha RS, Rajawat BS. Trachyspermum ammi. Pharmacogn Rev. 2012;6(11):56-60. 
Bhosale UA, Yegnanarayan R, Pophale PD, Zambare MR, Somani RS. Study of central nervous system depressant and behavioral activity of an ethanol extract of Achyranthes aspera (Agadha) in different animal models. Int J Appl Basic Med Res. 2011;1(2):104-8.

Ezhumalai K, Ilavarsan P, Mugundhan RM, Sathiyaraj U, Rajalakshmi AN. Transdermal patches in novel drug delivery system. Int J Pharm Technol. 2011;3(2):2402-2419.

Green MF, Nuechterlein KH, Gold JM, Barch DM, Cohen J, Essock S, et al. Approaching a consensus cognitive battery for clinical trials in schizophrenia: the NIMH-MATRICS conference to select cognitive domains and test criteria. Biol Psychiatry. 2004;56(5):301-7.

Kalaichelvi R, Thangabalan B, Rao DS, Jayachandran E. UV spectrophotometric determination of aripiprazole in bulk and pharmaceutical formulation. J Chem. 2009;6(S1):S87-90.

Kalinichev M, Rourke C, Daniels AJ, Grizzle MK, Britt CS, Ignar DM, et al. Characterisation of olanzapine-induced weight gain and effect of aripiprazole vs olanzapine on body weight and prolactin secretion in female rats. Psychopharmacology. 2005;182(2):220-31.

Łaszcz M, Witkowska A. Studies of phase transitions in the aripiprazole solid dosage form. J Pharm Biomed Anal. 2016;117:298-303.

Madhav NS, Shankar MU. A novel smart mucoadhesive biomaterial from Lallimantia royalena seed coat. Sci Asia. 2011;37:69-71.

Madhav NS, Yadav AP. A novel translabial platform utilizing bioexcipients from Litchi chinesis for the delivery of rosiglitazone maleate. Acta Pharm Sinica B. 2013;3(6):408-15.
Nalawade P, Mukherjee T, Kapoor S. Green synthesis of gold nanoparticles using glycerol as a reducing agent. Adv Nanoparticles. 2013;2(2):78-86.

Nekovarova T, Fajnerova I, Horacek J, Spaniel F. Bridging disparate symptoms of schizophrenia: a triple network dysfunction theory. Front Behav Neurosci. 2014;8:171.

Otsuka Pharmaceutical Co. L. Full prescribing informationAbilify (Aripiprazole), 2014. USFDA approved label of ABILIFY. [cited 2016 Nov. 08]. Available from: http://www. accessdata.fda.gov/drugsatfda_docs/label/2002/21436_Abilify_ lbl.pdf.

Sass LA, Parnas J. Schizophrenia, consciousness, and the self. Schizophrenia Bull. 2003;29(3):427-44.

Shakya P, Madhav NS, Shakya AK, Singh K. Palatal mucosa as a route for systemic drug delivery: A review. J Control Rel. 2011;151(1):2-9.

Shankar U, Madhav S. A smart oro-soft palate mucosal drug delivery: Credentials and future trends. Marmara Pharm J. 2015;19(3):208-21.

Varley H. Introductary collection of specimens and some general techniques. In: Practical clinical biochemistry. $4^{\text {th }}$ ed. New Delhi: CBS Publishers and Distributers; 2005.

Xu Y, Liu X, Lian R, Zheng S, Yin Z, Lu Y, et al. Enhanced dissolution and oral bioavailability of aripiprazole nanosuspensions prepared by nanoprecipitation/homogenization based on acid-base neutralization. Int J Pharm. 2012;438(1):28795.

Received for publication on $14^{\text {th }}$ July 2017 Accepted for publication on $27^{\text {th }}$ October 2017 